Check for updates

Cite this: RSC Adv., 2017, 7, 32850

Received 18th March 2017 Accepted 11th June 2017

DOI: 10.1039/c7ra03209a

rsc.li/rsc-advances

\section{Assembly of 1D coaxial nanoribbons into 2D multicolor luminescence array membrane endowed with tunable anisotropic electrical conductivity and magnetism via electrospinning $\dagger$}

\author{
Hong Shao, ${ }^{a}$ Wensheng Yu, ${ }^{a}$ Qianli Ma, ${ }^{\text {*a }}$ Xinlu Wang, ${ }^{a}$ Xiangting Dong, (DD *a \\ Zhelin Liu, ${ }^{a}$ Jinxian Wang, (DD ${ }^{a}$ Guixia Liu (D) and Limin Chang ${ }^{b}$
}

A flexible 2D color-tunable coaxial nanoribbon array membrane with anisotropic electrical conductivity and magnetism assembled by 1D coaxial nanoribbons is obtained via coaxial electrospinning technology using a specially designed coaxial spinneret. Each coaxial nanoribbon in the array is composed of an $\mathrm{Fe}_{3} \mathrm{O}_{4}$ nanoparticle (NPs)/polymethyl methacrylate (PMMA) magnetic core and $\left[\mathrm{Eu}(\mathrm{TTA})_{3}(\mathrm{TPPO})_{2}+\right.$ $\left.\mathrm{Tb}(\mathrm{TTA})_{3}(\mathrm{TPPO})_{2}\right] /$ polyaniline $(\mathrm{PANI}) / \mathrm{PMMA}[\mathrm{TTA}=2$-thenoyltrifluoroacetone radical, TPPO $=\operatorname{tris}(\mathrm{N}, \mathrm{N}-$ tetramethylene)phosphoric acid triamide] conductive photoluminescent shell, and the array membrane is formed by aligned coaxial nanoribbons. Tunable colors ranging from green to red can be achieved in the coaxial nanoribbon array membrane by modulating the mass ratio of $\mathrm{Eu}(\mathrm{TTA})_{3}(\mathrm{TPPO})_{2}, \mathrm{~Tb}(\mathrm{TTA})_{3}(\mathrm{TPPO})_{2}$, $\mathrm{PANI}$ and $\mathrm{Fe}_{3} \mathrm{O}_{4}$ NPs. Additionally, other functions such as magnetism and anisotropic electrical conductivity are conveniently exhibited by the coaxial nanoribbon array membrane to realize multifunctionality. The ratio of the conductivity parallel and perpendicular to the length direction of the nanoribbons is as high as five due to the unique nanostructure of the array membrane. Also, the magnetic performance, electrical conductivity and electrically conductive anisotropy of the coaxial nanoribbon array membrane can be tuned by modulating the contents of PANI and $\mathrm{Fe}_{3} \mathrm{O}_{4} \mathrm{NPs}$. The coaxial nanoribbon array membrane exhibits a much better luminescent performance and electrically conductive anisotropy than its counterpart composite nanoribbon array membrane. Furthermore, the design philosophy and synthetic method for the flexible coaxial nanoribbon array membrane provide a new and facile strategy for the preparation of color-tunable 2D nanomaterials with multifunctionality.

\section{Introduction}

Luminescent materials have received increasing attention due to their unique optical characteristics and stability, ${ }^{1-6}$ which have wide applications in various fields, such as solarenergy conversion, displays, light-emitting diodes, and biomedicine. ${ }^{7-11}$ Rare earth ions play an indispensable role in modern lighting and displays owing to the abundant emission colors based on their $4 \mathrm{f}-4 \mathrm{f}$ or $4 \mathrm{f}-5 \mathrm{~d}$ transitions. ${ }^{12-17}$ Specifically, the $\mathrm{Eu}^{3+}$ ion, as one of the most common and broadly used activators, primarily emits red color which originates from its characteristic transitional emissions of

${ }^{a}$ Key Laboratory of Applied Chemistry and Nanotechnology at Universities of Jilin Province, Changchun University of Science and Technology, Changchun 130022, China. E-mail: maqianlimail@163.com; dongxiangting888@163.com; Fax: +86 0431 85383815; Tel: +86043185582575

${ }^{b}$ Key Laboratory of Preparation and Application of Environmental Friendly Materials (Jilin Normal University), Ministry of Education, Changchun 130103, China

$\dagger$ Electronic supplementary information (ESI) available. See DOI: $10.1039 / \mathrm{c} 7 \mathrm{ra03209a}$
${ }^{5} \mathrm{D}_{0,1,2}{ }^{7} \mathrm{~F}_{J}(J=4,3,2,1$ and 0$) . \mathrm{Tb}^{3+}$-Doped phosphors are widely applied as green emitting materials based on the ${ }^{5} \mathrm{D}_{4}{ }^{-} \mathrm{F}_{5}$ transition of $\mathrm{Tb}^{3+}$ ions. ${ }^{18,19}$ By doping $\mathrm{Eu}^{3+}$ and $\mathrm{Tb}^{3+}$ ions, materials can emit multicolor light, which have wide and important applications in computer displays, lighting and medical equipment. For example, Li et al..$^{\mathbf{2 0 , 2 1}}$ prepared well defined LaOF crystals and LaOF hollow spheres. By codoping $\mathrm{Tb}^{3+}$ and $\mathrm{Eu}^{3+}$ ions into the LaOF host and modulating the doping concentration of the $\mathrm{Eu}^{3+}$ ions, tunable multicolor emissions were obtained under $379 \mathrm{~nm}$ irradiation. Leng et al. ${ }^{22}$ successfully synthesized sphere-like and cauliflower-like hexagonal-vaterite $\mathrm{LuBO}_{3}$ via a chemical conversion route. For the prepared $\mathrm{Eu}^{3+} / \mathrm{Tb}^{3+}$ doped $\mathrm{LuBO}_{3}$ phosphors, the color tones were tuned from green, to greenyellow and yellow, and then to red by changing the relative doping concentrations of the $\mathrm{Tb}^{3+}$ and $\mathrm{Eu}^{3+}$ ions. Liu et al. ${ }^{23}$ synthesized a white light-emitting $\mathrm{NaGdF}_{4}$ phosphor based on efficient energy transfer between $\mathrm{Tb}^{3+}$ and $\mathrm{Eu}^{3+}$ via the conventional hydrothermal process. For $\mathrm{NaGdF}_{4}: \mathrm{Tb}^{3+}, \mathrm{Eu}^{3+}$, white emission was realized in the single phase $\mathrm{NaGdF}_{4}$ host 
by reasonably adjusting the molar ratios of $\mathrm{Tb}^{3+}$ and $\mathrm{Eu}^{3+}$ under ultraviolet excitation.

Recently, there has been growing research interest in the design and fabrication of novel multifunctional materials since novel multifunctional nanocomposites provide the possibility for multifunctional properties and enhanced functionality. ${ }^{24-26}$ For the purpose of developing multifunctional nanomaterials, other functions such as magnetism and electrical conduction can be conveniently assembled into luminescent nanomaterials to realize multifunctionality. Anisotropically conductive composites are a class of green materials with different resistivities in various directions, which have potential applications as functional materials in the semiconductor industry. ${ }^{27,28} \mathrm{Ra}$ et al. ${ }^{29}$ synthesized multiwalled carbon nanotube (MWCNTs) embedded polyacrylonitrile nanofibers via electrospinning, and their conductivity parallel to the winding direction is three times higher than that perpendicular to the winding direction. Gong et al. ${ }^{30}$ studied the effect of carbon nanotube (CNT) alignment on the electrical conductivity anisotropy of CNT enhanced polymer composites. Their results showed that the anisotropic electrical property of aligned CNT/polymer composites is mainly affected by the anisotropic average conductive pathway density, which varies with the CNT alignment state in the polymer matrix. Thus, anisotropic conductive composites will have important applications in high density electrical connections in narrow spaces, such as in mobile phones, subminiature integrated circuits, microchips, and nanomachines.

Recently, some types of one-dimensional luminescent-electrical-magnetic multifunctional materials have been reported by scientists. Photoluminescent-electrical-magnetism trifunctional composite nanofibers, ${ }^{31}$ composite nanobelts, ${ }^{32}$ hollow nanofibers ${ }^{33,34}$ as well as electricity-magnetism and colortunable microbelts ${ }^{35}$ have been constructed via electrospinning. According to previous work, the direct contact of $\mathrm{RE}$ compounds with deep-colored materials results in a significant reduction in luminescent intensity. Thus, in order to obtain stronger photoluminescence, the luminescent material should be isolated from deep-colored materials.

Nanoribbons are a type of nanomaterial with a special morphology, ${ }^{36,37}$ which have attracted great interest from scientists due to their anisotropy, large width-thickness ratio, photoluminescence and electrical and magnetic properties. Electrospinning is one of the most promising, simple and efficient techniques for the production of viscous solutions or melts into continuous fibers or belts with controllable diameters down to the nano or submicron scale. ${ }^{38-42}$ Electrospun products have diverse and numerous potential applications, including filtration, optical and chemical sensors, biological scaffolds and electrode materials..$^{43-48}$

Herein, we prepare a novel coaxial nanoribbon array membrane composed of an $\mathrm{Fe}_{3} \mathrm{O}_{4} \mathrm{NPs} /$ polymethyl methacrylate (PMMA) core and $\mathrm{RE}(\mathrm{RE}=\mathrm{Eu}$ and $\mathrm{Tb})$ complexes/PANI/PMMA shell via electrospinning. By constructing type of structure, luminescent compounds can be effectively isolated from $\mathrm{Fe}_{3} \mathrm{O}_{4}$ NPs to avoid direct contact. Furthermore, anisotropic electrical conductivity and magnetism characteristics are introduced into the coaxial nanoribbon array membrane to achieve multifunctionality. Herein, magnetism allows the coaxial nanoribbon array membrane to be controlled under an external magnetic field. These characteristics allow the coaxial nanoribbon array membrane to be widely used in the fields of electromagnetic interference shielding, microwave absorption, ${ }^{49}$ etc. Furthermore, all the coaxial nanoribbons are arranged in the same direction by using a rolling aluminum rotary drum as the collector. It is expected that the resultant $\left[\mathrm{Fe}_{3} \mathrm{O}_{4} / \mathrm{PMMA}\right]$ @ $\left\{\left[\mathrm{Eu}(\mathrm{TTA})_{3}(\mathrm{TPPO})_{2}+\mathrm{Tb}(\mathrm{TTA})_{3}(\mathrm{TPPO})_{2}\right] / \mathrm{PANI} / \mathrm{PMMA}\right\}$ coaxial nanoribbon array membrane will possess a high electrical conductivity ratio between the conductivity parallel and perpendicular to the length direction of the nanoribbons. This new type of coaxial nanoribbon array membrane is ideally suited for application in high density electrical connections in narrow spaces, such as in mobile phones, subminiature integrated circuits, microchips and nano/micro-machines..$^{50,51}$ The structure, luminescence, anisotropic electrical conductivity and magnetism of the coaxial nanoribbon array membrane are investigated, and some satisfactory results are obtained.

\section{Experimental}

\subsection{Chemicals}

$\mathrm{Eu}_{2} \mathrm{O}_{3}$ (99.99\%), $\mathrm{Tb}_{4} \mathrm{O}_{7}$ (99.99\%), 2-thenoyltrifluoroacetone (HTTA), tris $(N, N$-tetramethylene)phosphoric acid triamide (TPPO), $\mathrm{FeCl}_{3} \cdot 6 \mathrm{H}_{2} \mathrm{O}, \mathrm{FeSO}_{4} \cdot 7 \mathrm{H}_{2} \mathrm{O}$, oleic acid (OA), $\mathrm{NH}_{4} \mathrm{NO}_{3}$, polyethylene glycol (PEG, $M_{\mathrm{r}} \approx 20000$ ), methyl methacrylate (MMA), ammonium persulfate (APS), benzoyl peroxide (BPO), aniline (ANI), (IS)-(+)-camphor-10 sulfonic acid (CSA), $N, N$ dimethylformamide (DMF), absolute alcohol, $\mathrm{CHCl}_{3}, \mathrm{HNO}_{3}$ and $\mathrm{NH}_{3} \cdot \mathrm{H}_{2} \mathrm{O}$. All of the chemicals were analytically pure and used as received.

\subsection{Preparation of $\operatorname{Tb}(\mathrm{TTA})_{3}(\mathrm{TPPO})_{2}$ powders, $\mathrm{Eu}(\mathrm{TTA})_{3}(\mathrm{TPPO})_{2}$ powders, PMMA and OA modified $\mathrm{Fe}_{3} \mathrm{O}_{4} \mathrm{NPs}$}

$\mathrm{Tb}(\mathrm{TTA})_{3}(\mathrm{TPPO})_{2}$ powders, $\mathrm{Eu}(\mathrm{TTA})_{3}(\mathrm{TPPO})_{2}$ powders and PMMA were prepared via a previous method and the corresponding description of the method was shown in the ESI. $\dagger$ The obtained OA modified $\mathrm{Fe}_{3} \mathrm{O}_{4}$ NPs were synthesized through a coprecipitation (see ESI $\dagger$ ). $\mathrm{Fe}_{3} \mathrm{O}_{4}$ NPs are spherical in shape (Fig. S1a $\dagger$ ), and the particle size is $13.37 \pm 0.14 \mathrm{~nm}$ (Fig. S1b $\dagger$ ). The saturation magnetization of the $\mathrm{Fe}_{3} \mathrm{O}_{4}$ nanoparticles after coating by OA is $39.38 \mathrm{emu} \mathrm{g}^{-1}$ (Fig. S2 $\dagger$ ).

\subsection{Preparation of spinning solutions}

To prepare the spinning solution for the synthesis of the conductive photoluminescent shell (named spinning solution I), PMMA (0.5 g) was added to a mixture of ANI, CSA, $\mathrm{CHCl}_{3}(6 \mathrm{~g})$ and DMF $(0.3 \mathrm{~g})$ under mechanical stirring for $48 \mathrm{~h}$. At the same time, APS was added to a separate mixture of $\mathrm{CHCl}_{3}(4 \mathrm{~g})$ and DMF $(0.4 \mathrm{~g})$ and stirred for $2 \mathrm{~h}$. Then the solutions were refrigerated at $0{ }^{\circ} \mathrm{C}$ for $1 \mathrm{~h}$. Subsequently, both solutions were mixed under mechanical agitation in a mixture of water and ice for another $2 \mathrm{~h}$. The reaction system was kept at $0{ }^{\circ} \mathrm{C}$ for $24 \mathrm{~h}$ to produce PANI by the polymerization of aniline..$^{52,53}$ Based on the 
Table 1 Compositions of spinning solution I

\begin{tabular}{|c|c|c|c|c|c|}
\hline \multirow[b]{2}{*}{$\begin{array}{l}\text { Spinning } \\
\text { solutions }\end{array}$} & \multicolumn{5}{|c|}{ Composition } \\
\hline & $\begin{array}{l}\mathrm{Eu}(\mathrm{TTA})_{3} \\
(\mathrm{TPPO})_{2} / \mathrm{g}\end{array}$ & $\begin{array}{l}\mathrm{Tb}(\mathrm{TTA})_{3} \\
(\mathrm{TPPO})_{2} / \mathrm{g}\end{array}$ & $\mathrm{ANI} / \mathrm{g}$ & $\mathrm{CSA} / \mathrm{g}$ & APS $/ g$ \\
\hline $\mathrm{S}_{\mathrm{a} 1}$ & 0.9 & 0 & 0.15 & 0.2809 & 0.3676 \\
\hline $\mathrm{S}_{\mathrm{a} 2}$ & 0.81 & 0.09 & 0.15 & 0.2809 & 0.3676 \\
\hline $\mathrm{S}_{\mathrm{a} 3}$ & 0.63 & 0.27 & 0.15 & 0.2809 & 0.3676 \\
\hline $\mathrm{S}_{\mathrm{a} 4}$ & 0.45 & 0.45 & 0.15 & 0.2809 & 0.3676 \\
\hline $\mathrm{S}_{\mathrm{a} 5}$ & 0.27 & 0.63 & 0.15 & 0.2809 & 0.3676 \\
\hline $\mathrm{S}_{\mathrm{a} 6}$ & 0.09 & 0.81 & 0.15 & 0.2809 & 0.3676 \\
\hline $\mathrm{S}_{\mathrm{a} 7}$ & 0 & 0.9 & 0.15 & 0.2809 & 0.3676 \\
\hline $\mathrm{S}_{\mathrm{a} 8}$ & 0.45 & 0.45 & 0.25 & 0.4682 & 0.6126 \\
\hline$S_{\mathrm{a} 9}$ & 0.45 & 0.45 & 0.35 & 0.6554 & 0.8578 \\
\hline
\end{tabular}

Table 2 Compositions of the spinning solution II

\begin{tabular}{lllll}
\hline \multirow{4}{*}{ Spinning solution } & \multicolumn{2}{l}{ Compositions } \\
\cline { 2 - 5 } & $\mathrm{Fe}_{3} \mathrm{O}_{4} / \mathrm{g}$ & $\mathrm{PMMA} / \mathrm{g}$ & $\mathrm{CHCl}_{3} / \mathrm{g}$ & $\mathrm{DMF} / \mathrm{g}$ \\
\hline $\mathrm{S}_{\mathrm{b} 1}$ & 0.5 & 0.5 & 9 & 0.9 \\
$\mathrm{~S}_{\mathrm{b} 2}$ & 1.0 & 0.5 & 9 & 0.9 \\
$\mathrm{~S}_{\mathrm{b} 3}$ & 1.5 & 0.5 & 9 & 0.9
\end{tabular}

reference, ${ }^{54}$ the mass percentage of $\mathrm{RE}(\mathrm{TTA})_{3}(\mathrm{TPPO})_{2}$ to PMMA of $180 \%$ was adopted to prepare the $\left[\mathrm{Fe}_{3} \mathrm{O}_{4} / \mathrm{PMMA}\right] @$ $\left\{\left[\mathrm{Eu}(\mathrm{TTA})_{3}(\mathrm{TPPO})_{2}+\mathrm{Tb}(\mathrm{TTA})_{3}(\mathrm{TPPO})_{2}\right] / \mathrm{PANI} / \mathrm{PMMA}\right\}$ coaxial nanoribbon array membrane. Certain amounts of $\mathrm{Eu}(\mathrm{TTA})_{3}(-$ TPPO $)_{2}$ and $\mathrm{Tb}(\mathrm{TTA})_{3}(\mathrm{TPPO})_{2}$ complexes were introduced into the above mixture under magnetic stirring for another $12 \mathrm{~h}$ at room temperature to obtain spinning solution I for the shell. The quantities of the materials used for the preparation of spinning solution I are tabulated in Table 1.

The other spinning solution (named spinning solution II) for the core of the coaxial nanoribbons was prepared as follows. Certain amounts of $\mathrm{Fe}_{3} \mathrm{O}_{4}$ NPs were dispersed in a mixed solvent of $\mathrm{CHCl}_{3}(9 \mathrm{~g})$ and $\mathrm{DMF}(0.9 \mathrm{~g})$ under ultrasonication for $15 \mathrm{~min}$, and then PMMA (0.5 g) was introduced to the above solution under mechanical agitation for $48 \mathrm{~h}$. To study the effects of $\mathrm{Fe}_{3} \mathrm{O}_{4}$ NPs on the properties of the coaxial nanoribbon array membrane, various amounts of $\mathrm{Fe}_{3} \mathrm{O}_{4}$ NPs were added to the solution. Table 2 presents the actual components of spinning solution II. The obtained coaxial nanoribbon array membrane was denoted as $\mathrm{S}_{\mathrm{b} y} @ \mathrm{~S}_{\mathrm{a} x}(x=1-9$ and $y=1-3)$.

\subsection{Fabrication of tunable multicolor luminescent- electrical-magnetism trifunctional coaxial nanoribbon array membrane}

A schematic of the electrospinning process is shown in Fig. 1. Spinning solutions I and II were loaded into the outer and inner plastic syringes, respectively. A positive high voltage direct current (DC) supply was connected to the carbon electrode which was immersed in spinning solution II. The ground terminal was connected to an aluminum rotary drum, which

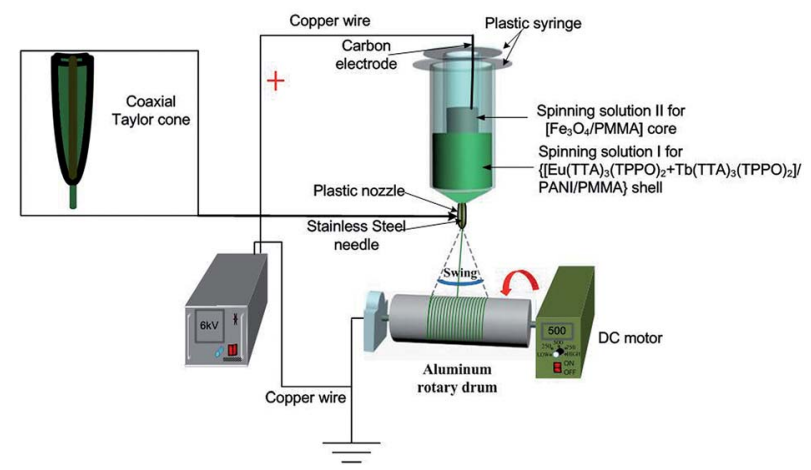

Fig. 1 Schematic illustration of the setup for the coaxial electrospinning process.

acted as the collector. The aluminum rotary drum with a length of $20 \mathrm{~cm}$ and diameter of $10 \mathrm{~cm}$ was placed at a distance of $18 \mathrm{~cm}$ from the plastic spinneret, fixed horizontally, and the rotation speed was $500 \mathrm{rpm}$. The voltage was tuned to about 6 $\mathrm{kV}$. The coaxial nanoribbons swung in the air due to the instability of the electrospinning process, and an array membrane with a certain width was collected on the surface of the aluminum rotary drum.

\subsection{Fabrication of $\mathrm{Fe}_{3} \mathrm{O}_{4} /\left[\mathrm{Eu}(\mathrm{TTA})_{3}(\mathrm{TPPO})_{2}+\right.$}

$\left.\mathrm{Tb}(\mathrm{TTA})_{3}(\mathrm{TPPO})_{2}\right] /$ PANI/PMMA composite nanoribbon array membrane

For comparison with the coaxial nanoribbon array membrane, an $\mathrm{Fe}_{3} \mathrm{O}_{4} /\left[\mathrm{Eu}(\mathrm{TTA})_{3}(\mathrm{TPPO})_{2}+\mathrm{Tb}(\mathrm{TTA})_{3}(\mathrm{TPPO})_{2}\right] / \mathrm{PANI} / \mathrm{PMMA}$ composite nanoribbon array membrane was fabricated by blending the $\mathrm{S}_{\mathrm{a} 4}$ and $\mathrm{S}_{\mathrm{b} 1}$ solutions together, and electrospinning them via conventional single-spinneret electrospinning. The other conditions were the same as that for the fabrication of the coaxial nanoribbon array membrane.

\subsection{Characterization}

The as-prepared $\mathrm{Fe}_{3} \mathrm{O}_{4}$ NPs and $\left[\mathrm{Fe}_{3} \mathrm{O}_{4} / \mathrm{PMMA}\right] @\left\{\left[\mathrm{Eu}(\mathrm{TTA})_{3}(-\right.\right.$ TPPO $\left.\left.)_{2}+\mathrm{Tb}(\mathrm{TTA})_{3}(\mathrm{TPPO})_{2}\right] / \mathrm{PANI} / \mathrm{PMMA}\right\}$ coaxial nanoribbon array membrane and composite nanoribbon array membrane were characterized via X-ray powder diffraction (XRD) on a D8 FOCUS diffractometer ( $\mathrm{Cu} \mathrm{K} \alpha$ radiation, $\lambda=0.154 \mathrm{~nm}$, operated at $40 \mathrm{kV}$ and $20 \mathrm{~mA}$ ). The morphology and size of the $\mathrm{Fe}_{3} \mathrm{O}_{4} \mathrm{NPs}$ and coaxial nanoribbon array membrane were observed via transmission electron microscopy (TEM, Jeol, JEM-2010) and scanning electron microscopy (SEM, JSM-7610F) with an energydispersive X-ray spectrometer (EDS) attached to the SEM. The inner structures of the coaxial nanoribbon array membrane were studied utilizing a CVM500E model biological microscope (BM). Fluorescence and the luminescence decay curves were investigated on an F-7000 Hitachi fluorescence spectrophotometer. A vibrating sample magnetometer (VSM) purchased from Quantum Design Inc. was used to determine magnetism. A Hall Effect Measurement System was adopted to detect the anisotropic electrical conductivity properties of the samples. 
UV-vis absorption spectra were recorded on a Shimadzu UV1240 spectrophotometer.

\section{Results and discussion}

\subsection{X-ray diffraction}

The XRD patterns of the as-obtained $\mathrm{Fe}_{3} \mathrm{O}_{4} \mathrm{NPs},\left[\mathrm{Fe}_{3} \mathrm{O}_{4} / \mathrm{PMMA}\right]$ (a $\left\{\left[\mathrm{Eu}(\mathrm{TTA})_{3}(\mathrm{TPPO})_{2}+\mathrm{Tb}(\mathrm{TTA})_{3}(\mathrm{TPPO})_{2}\right] / \mathrm{PANI} / \mathrm{PMMA}\right\}$ coaxial nanoribbon array membrane $\left(\mathrm{S}_{\mathrm{b} 1} @ \mathrm{~S}_{\mathrm{a} 4}\right)$ and composite nanoribbon array membrane are given in Fig. 2. The diffraction peaks of the as-prepared $\mathrm{Fe}_{3} \mathrm{O}_{4}$ NPs are readily indexed to the cubic phase of $\mathrm{Fe}_{3} \mathrm{O}_{4}$ (PDF 88-0866). Obviously, only the characteristic peaks of $\mathrm{Fe}_{3} \mathrm{O}_{4}$ can be detected in the samples, and no other impurities peaks (e.g., $\mathrm{Fe}_{2} \mathrm{O}_{3}$ and $\mathrm{FeO}(\mathrm{OH})$ ) are observed, which implies that a pure $\mathrm{Fe}_{3} \mathrm{O}_{4}$ phase was formed. The analysis results of the coaxial nanoribbon array membrane and composite nanoribbon array membrane indicate that they both contain $\mathrm{Fe}_{3} \mathrm{O}_{4}$ NPs, but their intensity is relatively low because of the existence of other amorphous substances.

\subsection{Morphology and structure}

Fig. 3a and $b$ show the SEM images of the coaxial nanoribbon array membrane at low and high magnification, respectively, which reveal that the array membrane consists of well aligned coaxial nanoribbons. The coaxial nanoribbons are $4.48 \pm 0.03$ $\mu \mathrm{m}$ in width (Fig. 3c) and $408.12 \pm 3.87 \mathrm{~nm}$ in thickness (Fig. 3d). In addition, it can be observed that nearly all the broadsides of the coaxial nanoribbons in the array membrane face upwards with the rare exception. The reason for this may be that such an arrangement would cause the coaxial nanoribbons to be lay in a more stable and low potential energy state on the aluminum rotary drum. The internal structure of the coaxial nanoribbons in the array membrane was investigated via $\mathrm{BM}$ observation, as presented in Fig. 3e. A distinct core-shell structure is observed with a core width of $c a .1 .5 \mu \mathrm{m}$. The core includes many deep-colored $\mathrm{Fe}_{3} \mathrm{O}_{4}$ NPs and the shell of the coaxial nanoribbons is blackish green due to the existence of PANI.

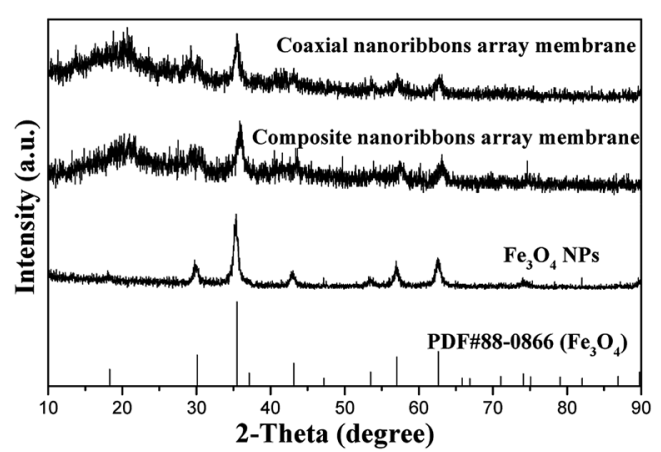

Fig. 2 XRD patterns of the $\mathrm{Fe}_{3} \mathrm{O}_{4} \mathrm{NPs}$, $\left[\mathrm{Fe}_{3} \mathrm{O}_{4} / \mathrm{PMMA}\right] \propto\left\{\left[\mathrm{Eu}(T T A)_{3}(-\right.\right.$ $\left.\left.\mathrm{TPPO})_{2}+\mathrm{Tb}(\mathrm{TTA})_{3}(\mathrm{TPPO})_{2}\right] / \mathrm{PANI} / \mathrm{PMMA}\right\}$ coaxial nanoribbon array membrane $\left(\mathrm{S}_{\mathrm{b}_{1}}\left(\mathrm{CS}_{\mathrm{a} 4}\right)\right.$, and composite nanoribbon array membrane with the PDF standard card of $\mathrm{Fe}_{3} \mathrm{O}_{4}$
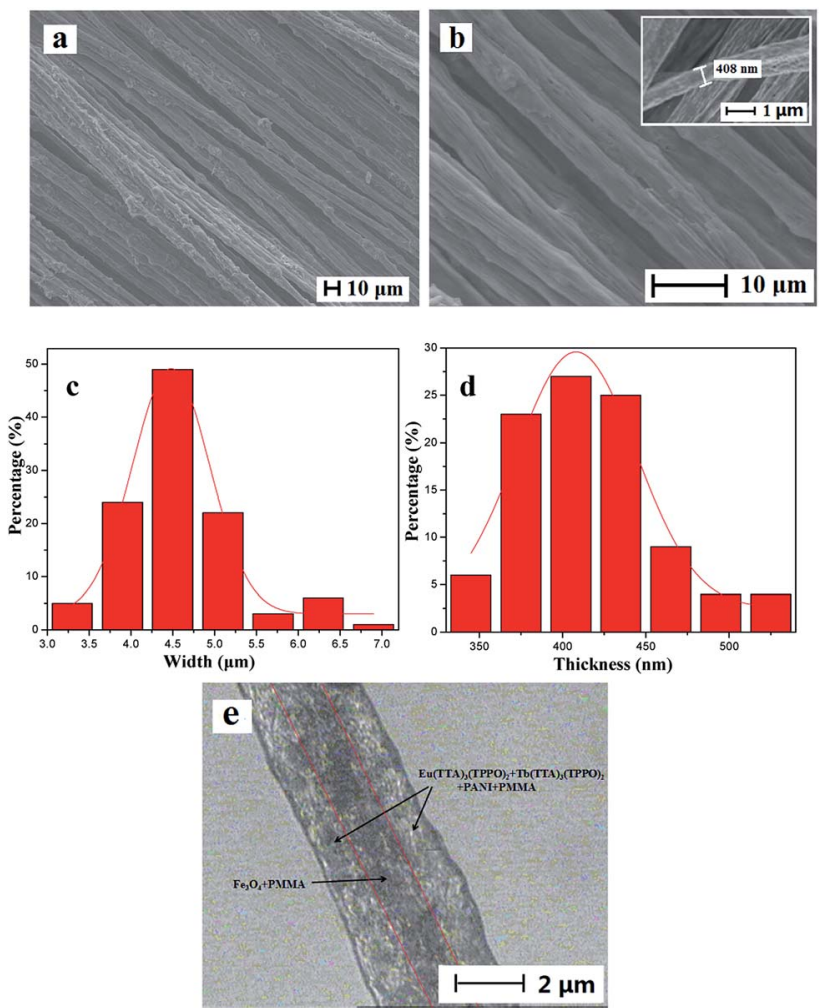

Fig. 3 SEM images of $\left[\mathrm{Fe}_{3} \mathrm{O}_{4} / \mathrm{PMMA}\right] @\left\{\left[\mathrm{Eu}(T \mathrm{TA})_{3}(\mathrm{TPPO})_{2}+\right.\right.$ $\mathrm{Tb}(\mathrm{TTA})_{3}(\mathrm{TPPO})_{2}$ ]/PANI/PMMA\}coaxial nanoribbon array membrane $\left(\mathrm{S}_{\mathrm{b}_{1}} \mathrm{CS}_{\mathrm{a} 4}\right.$; (a) low magnification and (b) high magnification); histograms of the width (c) and thickness (d) distributions; and BM image (e) of a single $\left[\mathrm{Fe}_{3} \mathrm{O}_{4} / \mathrm{PMMA}\right] @\left\{\left[\mathrm{Eu}(\mathrm{TTA})_{3}(\mathrm{TPPO})_{2}+\mathrm{Tb}(\mathrm{TTA})_{3}(\mathrm{TPPO})_{2}\right] / \mathrm{PANI} /\right.$ PMMA\}coaxial nanoribbon; the inset of (b) shows the thickness of a single coaxial nanoribbon.

To further study the structure of the coaxial nanoribbons in the array, EDS line-scan analysis tests were carried out. As seen from Fig. 4, elemental $\mathrm{S}, \mathrm{Fe}, \mathrm{Eu}$ and $\mathrm{Tb}$ represent CSA doped
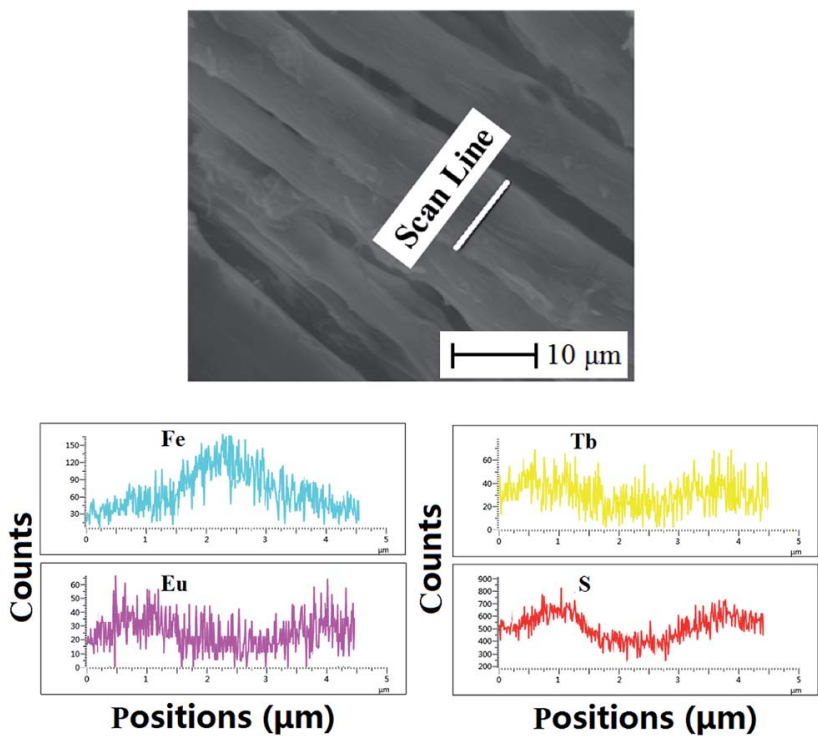

Fig. 4 EDS line-scan analysis of single $\left[\mathrm{Fe}_{3} \mathrm{O}_{4} / \mathrm{PMMA}\right] @\left\{\left[\mathrm{Eu}(\mathrm{TTA})_{3}(-\right.\right.$ $\mathrm{TPPO}_{2}+\mathrm{Tb}(\mathrm{TTA})_{3}(\mathrm{TPPO})_{2}$ ]/PANI/PMMA 3 coaxial nanoribbons in array. 

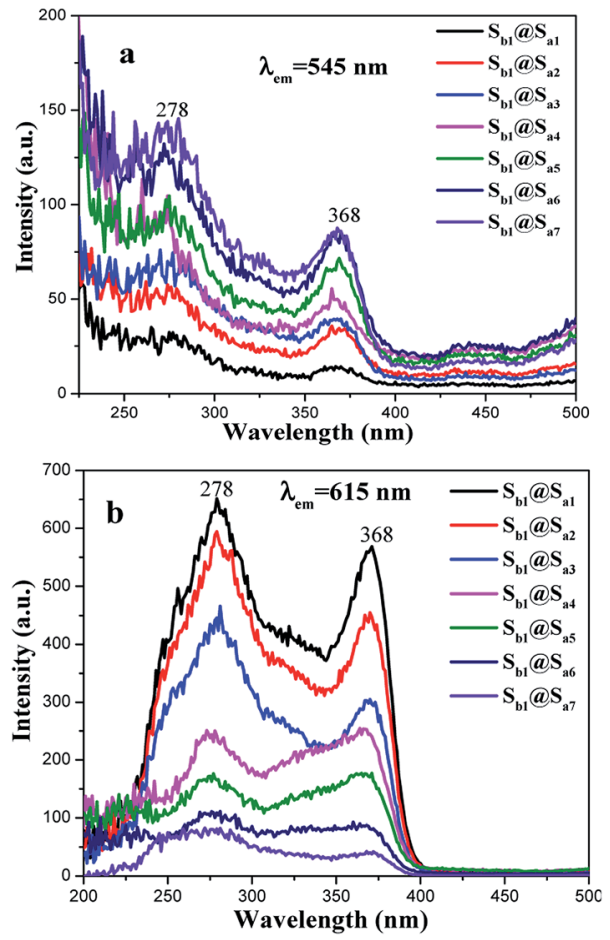

Fig. 5 Excitation spectra of samples $\mathrm{S}_{\mathrm{b} 1} \mathrm{aS}_{\mathrm{ax}}(x=1-7)$ with the monitored wavelengths of $545 \mathrm{~nm}$ (a) and $615 \mathrm{~nm}$ (b)

PANI, $\mathrm{Fe}_{3} \mathrm{O}_{4}, \mathrm{Eu}(\mathrm{TTA})_{3}(\mathrm{TPPO})_{2}$ and $\mathrm{Tb}(\mathrm{TTA})_{3}(\mathrm{TPPO})_{2}$, respectively. Fe element exists in the middle domain of the coaxial nanoribbon. In the middle domain of the coaxial nanoribbon, the contents of $\mathrm{S}, \mathrm{Tb}$ and Eu elements are lower than those on both sides, which means that PANI and $\operatorname{RE}(\mathrm{TTA})_{3}(\mathrm{TPPO})_{2}(\mathrm{RE}=$ $\mathrm{Tb}$ and $\mathrm{Eu}$ ) only exist in the top and bottom surfaces of the middle domain of the coaxial nanoribbon. It is also discovered that elemental S, $\mathrm{Tb}$ and Eu without elemental Fe are dispersed on both sides of the coaxial nanoribbon. These results further confirm the coaxial structure of the coaxial nanoribbon.

\subsection{Photoluminescence property}

A series of coaxial nanoribbon array membranes (samples $\left.\mathrm{S}_{\mathrm{b} 1} @ \mathrm{~S}_{\mathrm{ax}}, x=1-7\right)$ doped with various contents of $\mathrm{RE}(\mathrm{TTA})_{3}(-$ $\mathrm{TPPO})_{2}$ were fabricated to study the fluorescent performance of the membrane when the content of PANI to PMMA is 30\% and $\mathrm{Fe}_{3} \mathrm{O}_{4}$ to PMMA is $1: 1$. As illustrated in Fig. 5 and 6 , a wide band is observed in the region of $200-400 \mathrm{~nm}$ with a maximum at $278 \mathrm{~nm}$, which could be attributed to the $\pi \rightarrow \pi^{*}$ electron transition of the ligands. With an increase in $\mathrm{Tb}(\mathrm{TTA})_{3}(\mathrm{TPPO})_{2}$ concentration, the fluorescence intensity gradually increases when the monitored wavelength is $545 \mathrm{~nm}$ (Fig. 5a). Similarly, the fluorescence intensity increases with an increase in the content of $\mathrm{Eu}(\mathrm{TTA})_{3}(\mathrm{TPPO})_{2}$ when the monitored wavelength is $615 \mathrm{~nm}$ (Fig. 5b).

Under $278 \mathrm{~nm}$ excitation, the emission spectra of the coaxial nanoribbon array membrane doped with various contents of $\operatorname{RE}(\mathrm{TTA})_{3}(\mathrm{TPPO})_{2}$ have several emissions peaks. The peaks located at 490 and $545 \mathrm{~nm}$ are due to the ${ }^{5} \mathrm{D}_{4} \rightarrow{ }^{7} \mathrm{~F}_{J}(J=6$ and 5)
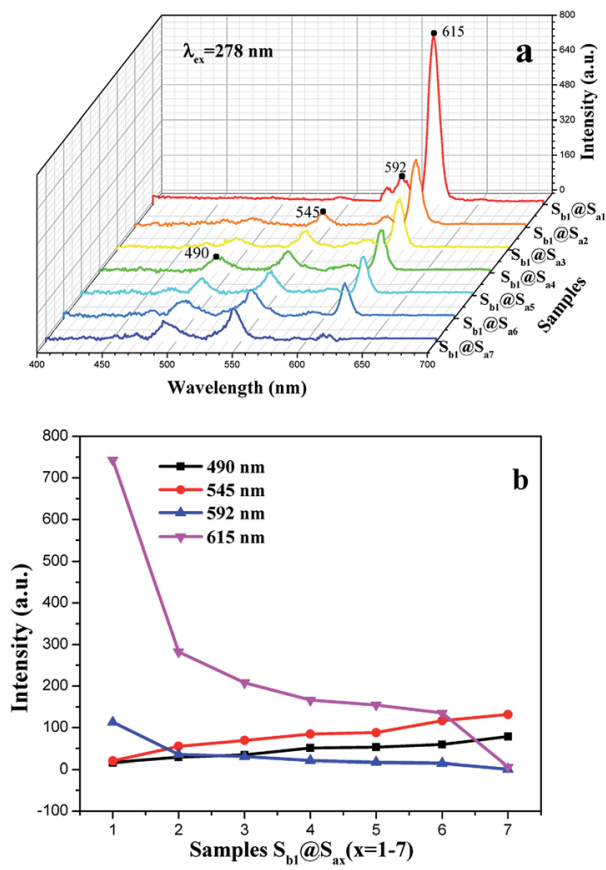

Fig. 6 Emission spectra (a) of samples $\mathrm{S}_{\mathrm{b} 1} \mathrm{aS}_{\mathrm{ax}}(x=1-7)$ at the PANI percentage of $30 \%$ and $\mathrm{Fe}_{3} \mathrm{O}_{4}$ to PMMA ratio of $1: 1$ and relationship between the RE complexes content and intensity of the luminescent peaks of the samples (b).

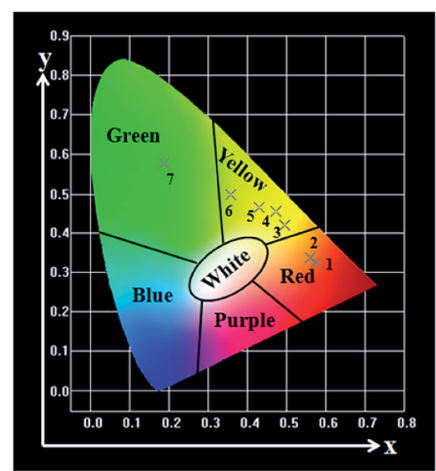

Fig. $7 \mathrm{CIE}$ chromaticity coordinate diagram of the samples $\mathrm{S}_{\mathrm{b} 1} \mathrm{aS}_{\mathrm{ax}}(x$ $=1-7)$ upon excitation at $278 \mathrm{~nm}$.

transitions of $\mathrm{Tb}^{3+}$, whereas the peaks at 592 and $615 \mathrm{~nm}$ are ascribed to the ${ }^{5} \mathrm{D}_{0} \rightarrow{ }^{7} \mathrm{~F}_{J}(J=1,2)$ transitions of $\mathrm{Eu}^{3+}$ (Fig. 6a). It is directly observed that the fluorescence intensity of the $\mathrm{Tb}^{3+}$ ions enhances gradually with an increase in $\mathrm{Tb}^{3+}$ concentration, whereas the emission peak of the $\mathrm{Eu}^{3+}$ ions gradually decreases. The variation trends are depicted in Fig. 6b. The energy distribution results in a change in the fluorescence intensities of $\mathrm{Eu}^{3+}$ and $\mathrm{Tb}^{3+}$. Since the matrix can absorb energy and the total mass of $\operatorname{RE}(\mathrm{TTA})_{3}(\mathrm{TPPO})_{2}(\mathrm{RE}=\mathrm{Eu}$ and $\mathrm{Tb})$ is fixed, the energy assigned to $\mathrm{Eu}^{3+}$ increased with an increase in $\mathrm{Eu}^{3+}$ concentration, thus resulting in the enhanced fluorescence intensity at 592 and $615 \mathrm{~nm}$. Whereas, the energy assigned to $\mathrm{Tb}^{3+}$ decreased and the fluorescence intensities at 490 and $545 \mathrm{~nm}$ were weakened. Hence, changing the contents of the 
Table $3 \mathrm{ClE}$ chromaticity coordinates $(x, y)$ for samples $\mathrm{S}_{\mathrm{b} 1} \mathrm{QS}_{\mathrm{ax}}(x=$ 1-7) upon excitation at $278 \mathrm{~nm}$

\begin{tabular}{llll}
\hline Label & Samples & Concentration & CIE $(x, y)$ \\
\hline 1 & $\mathrm{~S}_{\mathrm{b} 1} @ \mathrm{~S}_{\mathrm{a} 1}$ & $100 \% \mathrm{Eu}, 0 \% \mathrm{~Tb}$ & $(0.575,0.325)$ \\
2 & $\mathrm{~S}_{\mathrm{b} 1} @ \mathrm{~S}_{\mathrm{a} 2}$ & $90 \% \mathrm{Eu}, 10 \% \mathrm{~Tb}$ & $(0.559,0.338)$ \\
3 & $\mathrm{~S}_{\mathrm{b} 1} @ \mathrm{~S}_{\mathrm{a} 3}$ & $70 \% \mathrm{Eu}, 30 \% \mathrm{~Tb}$ & $(0.494,0.419)$ \\
4 & $\mathrm{~S}_{\mathrm{b} 1} @ \mathrm{~S}_{\mathrm{a} 4}$ & $50 \% \mathrm{Eu}, 50 \% \mathrm{~Tb}$ & $(0.472,0.455)$ \\
5 & $\mathrm{~S}_{\mathrm{b} 1} @ \mathrm{~S}_{\mathrm{a} 5}$ & $30 \% \mathrm{Eu}, 70 \% \mathrm{~Tb}$ & $(0.430,0.465)$ \\
6 & $\mathrm{~S}_{\mathrm{b} 1} @ \mathrm{~S}_{\mathrm{a} 6}$ & $90 \% \mathrm{Eu}, 10 \% \mathrm{~Tb}$ & $(0.357,0.498)$ \\
7 & $\mathrm{~S}_{\mathrm{b} 1} @ \mathrm{~S}_{\mathrm{a} 7}$ & $0 \% \mathrm{Eu}, 100 \% \mathrm{~Tb}$ & $(0.187,0.578)$
\end{tabular}

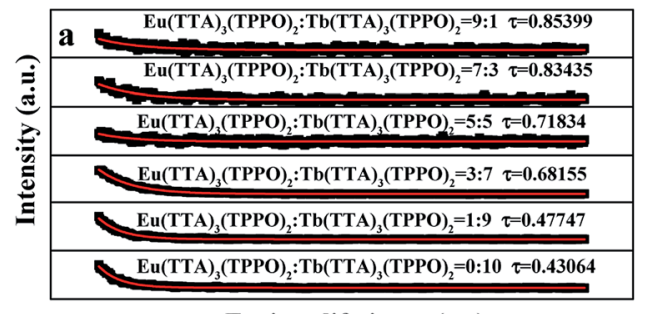

Exciton lifetime $\tau(\mathrm{ms})$

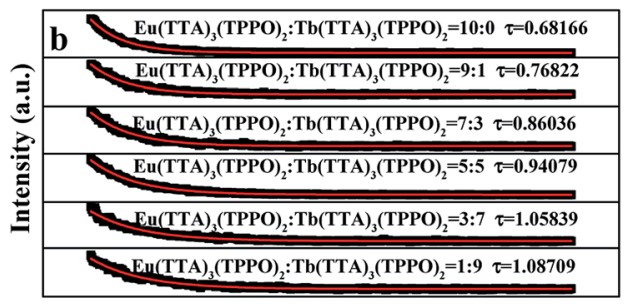

Exciton lifetime $\tau(\mathrm{ms})$

Fig. 8 Lifetime curves of $\mathrm{Tb}^{3+}(\mathrm{a})$ and $\mathrm{Eu}^{3+}(\mathrm{b})$ in the samples $\mathrm{S}_{\mathrm{b} 1} \mathrm{aS}_{\mathrm{ax}}(x$ $=1-7)$.

$\mathrm{Eu}(\mathrm{TTA})_{3}(\mathrm{TPPO})_{2}$ and $\mathrm{Tb}(\mathrm{TTA})_{3}(\mathrm{TPPO})_{2}$ complexes in the coaxial nanoribbon array membrane can tune its emission spectrum.

The CIE chromaticity diagram ${ }^{55,56}$ of the coaxial nanoribbon array membrane with different mass ratios of $\mathrm{Eu}(\mathrm{TTA})_{3}(\mathrm{TPPO})_{2}$ to $\mathrm{Tb}(\mathrm{TTA})_{3}(\mathrm{TPPO})_{2}$ complexes upon $278 \mathrm{~nm}$ UV lamp excitation were calculated using the CIE software based on the corresponding emission spectra shown in Fig. 6a, as represented in Fig. 7, and the data are given in Table 3. The intriguing finding is that the fluorescence color can be tuned from red, yellow to green by modulating the mass ratio of the $\mathrm{Eu}(\mathrm{TTA})_{3}(\mathrm{TPPO})_{2}$ to $\mathrm{Tb}(\mathrm{TTA})_{3}(\mathrm{TPPO})_{2}$ complexes.

The fluorescence lifetime curves of $\mathrm{Tb}^{3+}$ and $\mathrm{Eu}^{3+}$ were measured by monitoring at the wavelengths of $545 \mathrm{~nm}$ and $615 \mathrm{~nm}$ with excitation of $278 \mathrm{~nm}$ as shown in Fig. 8, respectively. Intriguingly, the curves correspond to the singleexponential decay:

$$
I_{t}=I_{0} \exp (-t / \tau)
$$

where, $I_{t}$ represents the intensity at time $t, I_{0}$ is the initial intensity, $t$ is the decay time and $\tau$ is the exciton lifetime. As indicated in Fig. 8, the fluorescence lifetime values of $\mathrm{Tb}^{3+}$ gradually increase with a decrease in $\mathrm{Tb}^{3+}$ content. The same conclusion can be drawn for the $\mathrm{Eu}^{3+}$ ions, where the lifetime of the $\mathrm{Eu}^{3+}$ ions increases with a decrease in $\mathrm{Eu}^{3+}$ content. The
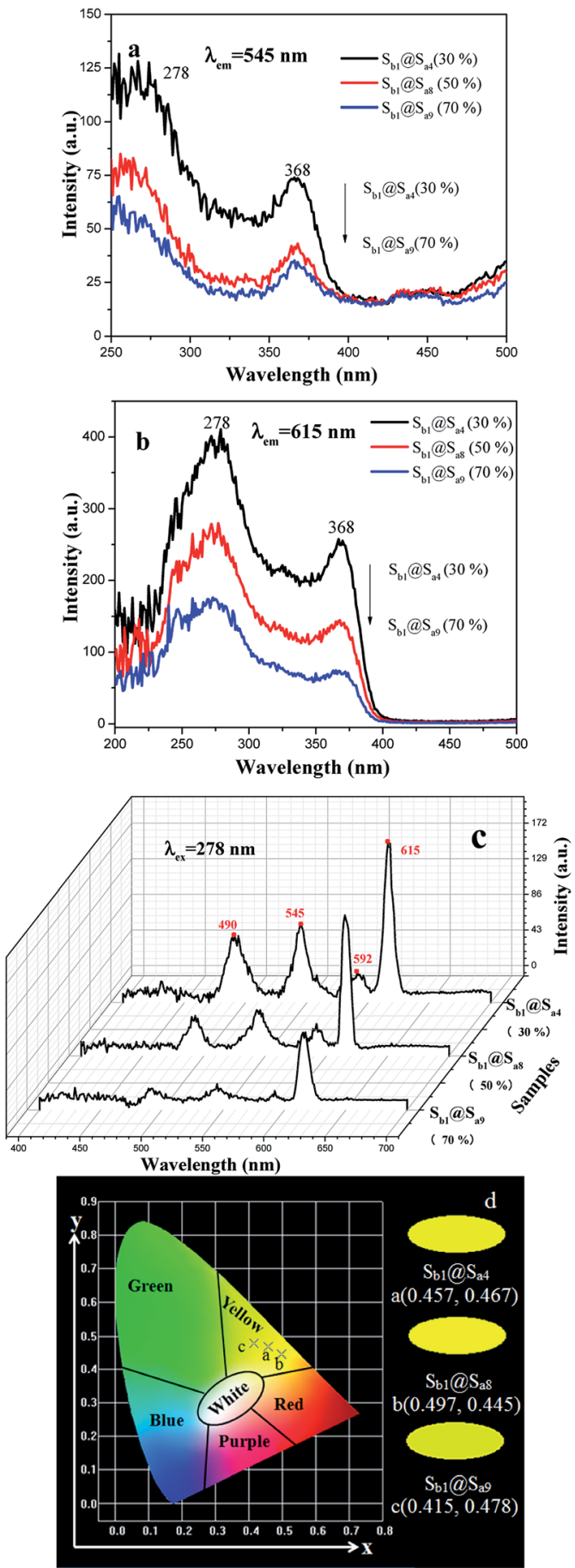

Fig. 9 Excitation spectra with the monitoring wavelengths of $545 \mathrm{~nm}$ (a) and $615 \mathrm{~nm}$ (b); emission spectra (c) and CIE chromaticity coordinate diagram (d) of the $\left[\mathrm{Fe}_{3} \mathrm{O}_{4} / \mathrm{PMMA}\right] @\left\{\left[\mathrm{Eu}(\mathrm{TTA})_{3}(\mathrm{TPPO})_{2}+\right.\right.$ $\mathrm{Tb}(\mathrm{TTA})_{3}(\mathrm{TPPO})_{2}$ ]/PANI/PMMA\} coaxial nanoribbon array membrane doped with different contents of PANI.

following are the possible reasons for this result. When the concentration of the $\mathrm{Tb}(\mathrm{TTA})_{3}(\mathrm{TPPO})_{2}$ complex in the coaxial nanoribbon array membrane decreases and the relative concentration of $\mathrm{Eu}(\mathrm{TTA})_{3}(\mathrm{TPPO})_{2}$ increases, the distance among the $\mathrm{Tb}^{3+}$ ions in the $\mathrm{Tb}$ (TTA $)_{3}(\mathrm{TPPO})_{2}$ molecular clusters in the coaxial nanoribbon array membrane increases, which 

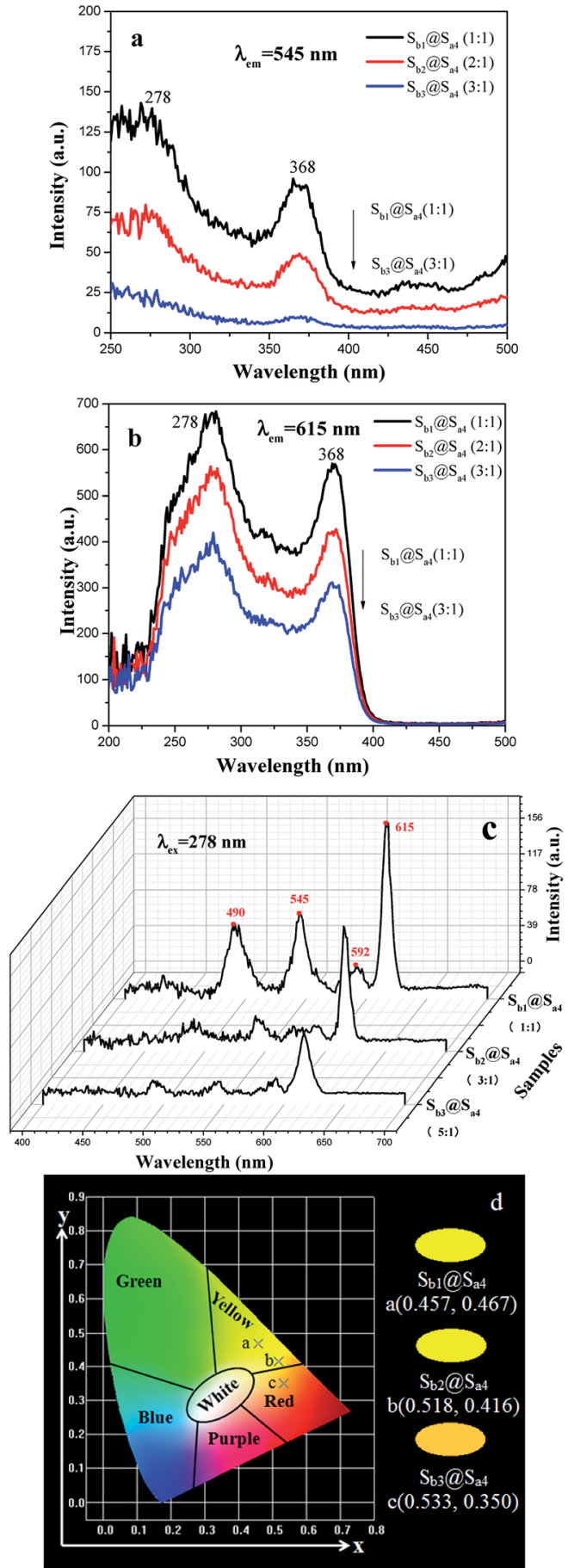

Fig. 10 Excitation spectra with the monitoring wavelengths of $545 \mathrm{~nm}$ (a) and $615 \mathrm{~nm}$ (b), emission spectra (c) and CIE chromaticity coordinate diagram (d) of $\left[\mathrm{Fe}_{3} \mathrm{O}_{4} / \mathrm{PMMA}\right] @\left\{\left[\mathrm{Eu}(\mathrm{TTA})_{3}(\mathrm{TPPO})_{2}+\mathrm{Tb}(\mathrm{TTA})_{3}(-\right.\right.$ TPPO) ${ }_{2}$ /PANI/PMMA\} coaxial nanoribbon array membrane doped with different contents of $\mathrm{Fe}_{3} \mathrm{O}_{4}$ NPs.

leads to a reduction in the energy transfer among $\mathrm{Tb}^{3+}$ to $\mathrm{Tb}^{3+}$ and prolongs the fluorescence lifetime of $\mathrm{Tb}^{3+}$. On the other hand, adding more $\mathrm{Eu}(\mathrm{TTA})_{3}(\mathrm{TPPO})_{2}$ into PMMA leads to the formation of more aggregates of $\mathrm{Eu}(\mathrm{TTA})_{3}(\mathrm{TPPO})_{2}$. The exciton migration between the $\mathrm{Eu}(\mathrm{TTA})_{3}(\mathrm{TPPO})_{2}$ molecules shortens the fluorescence lifetime of $\mathrm{Eu}^{3+} .5^{7}$

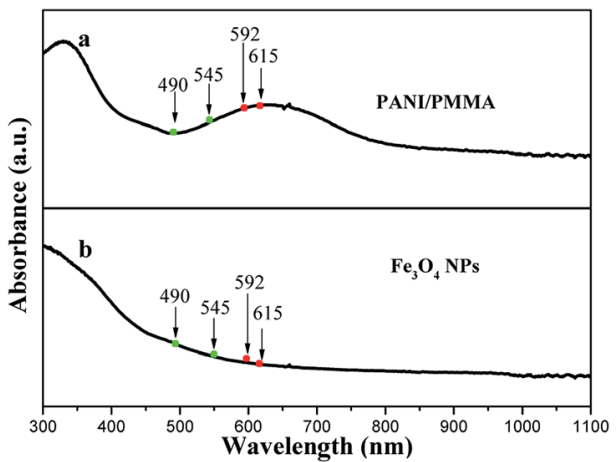

Fig. 11 Ultraviolet-visible absorption spectra of PANI/PMMA (a) and $\mathrm{Fe}_{3} \mathrm{O}_{4} \mathrm{NPs}(\mathrm{b})$

Besides, the fluorescent properties of the $\left[\mathrm{Fe}_{3} \mathrm{O}_{4} / \mathrm{PMMA}\right]$ @ $\left\{\left[\mathrm{Eu}(\mathrm{TTA})_{3}(\mathrm{TPPO})_{2}+\mathrm{Tb}(\mathrm{TTA})_{3}(\mathrm{TPPO})_{2}\right] / \mathrm{PANI} / \mathrm{PMMA}\right\}$ coaxial nanoribbon array membrane with different PANI contents
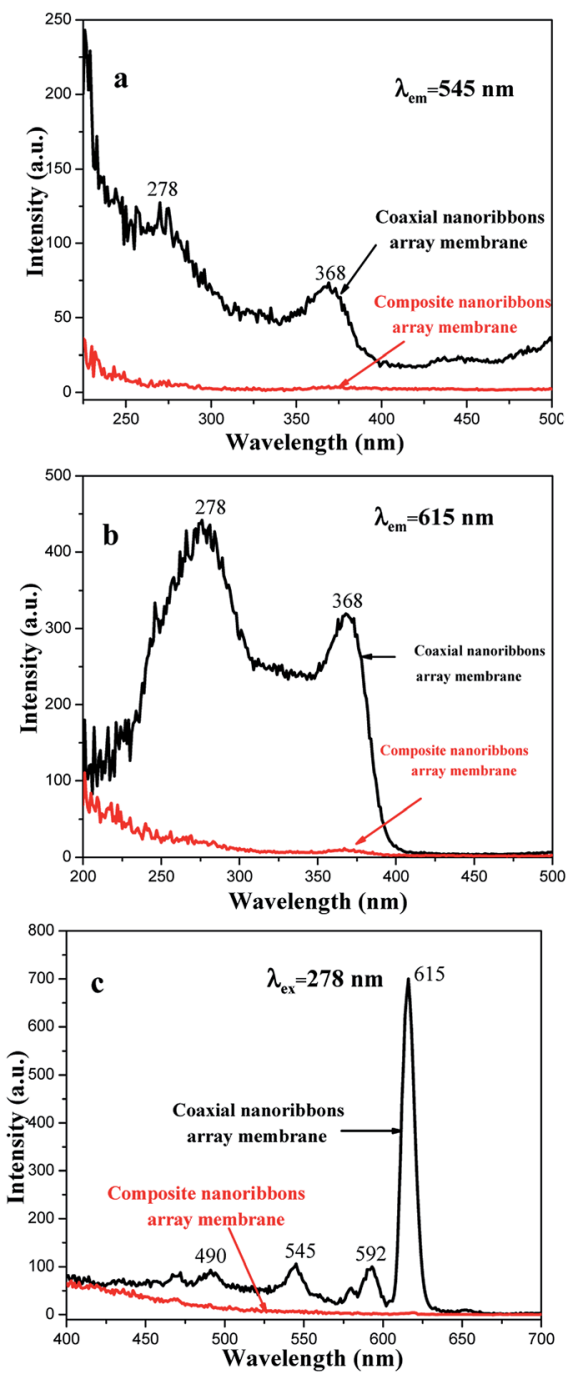

Fig. 12 Excitation spectra with the monitoring wavelengths of $545 \mathrm{~nm}$ (a) and $615 \mathrm{~nm}$ (b), and emission spectra (c) of the coaxial nanoribbon array membrane $\left(\mathrm{S}_{\mathrm{b} 1} \mathrm{QS}_{\mathrm{a} 4}\right)$ and its counterpart composite nanoribbon array membrane. 
$\left(\mathrm{S}_{\mathrm{b} 1} @ \mathrm{~S}_{\mathrm{a} 4}, \mathrm{~S}_{\mathrm{b} 1} @ \mathrm{~S}_{\mathrm{a} 8}\right.$ and $\left.\mathrm{S}_{\mathrm{b} 1} @ \mathrm{~S}_{\mathrm{a} 9}\right)$ were also studied at the $\mathrm{Fe}_{3} \mathrm{O}_{4}$ to PMMA ratio of $1: 1$. It can be seen from Fig. $9 \mathrm{a}-\mathrm{c}$ that fluorescence intensity diminishes with an increase in the content of PANI. Fig. 9d displays the CIE chromaticity diagram of the coaxial nanoribbon array membranes with different PANI contents upon $278 \mathrm{~nm}$ UV lamp excitation. It can be found that the luminescence color tunes more green with the addition of more PANI owing to the stronger absorption of red light by PANI. Similarly, when the amount of $\mathrm{Fe}_{3} \mathrm{O}_{4}$ NPs $\left(\mathrm{S}_{\mathrm{b} 1} @ \mathrm{~S}_{\mathrm{a} 4}\right.$, $\mathrm{S}_{\mathrm{b} 2} @ \mathrm{~S}_{\mathrm{a} 4}$ and $\mathrm{S}_{\mathrm{b} 3} @ \mathrm{~S}_{\mathrm{a} 4}$ ) increases, both excitation and emission intensities of the coaxial nanoribbons decrease (Fig. 10a-c). Fig. 10d presents the CIE coordinate diagram of coaxial nanoribbon array membrane containing different $\mathrm{Fe}_{3} \mathrm{O}_{4}$ contents upon $278 \mathrm{~nm} \mathrm{UV} \mathrm{lamp} \mathrm{excitation.} \mathrm{It} \mathrm{can} \mathrm{be} \mathrm{found} \mathrm{that} \mathrm{the}$ luminescence color of the coaxial nanoribbon array membrane could be shifted with the addition of more $\mathrm{Fe}_{3} \mathrm{O}_{4}$.

The above results can be explained by the light absorption of $\mathrm{Fe}_{3} \mathrm{O}_{4}$ NPs and PANI. The absorption spectra of the $\mathrm{Fe}_{3} \mathrm{O}_{4}$ NPs and PANI are shown in Fig. 11. It can be observed that PANI doped PMMA and $\mathrm{Fe}_{3} \mathrm{O}_{4}$ NPs strongly absorb light in the ultraviolet $(<400 \mathrm{~nm})$ and visible $(400-800 \mathrm{~nm})$ light regions. Therefore, the exciting light and emitting light are absorbed by the PANI and $\mathrm{Fe}_{3} \mathrm{O}_{4}$ NPs, which results in the fact that the intensities of exciting and emitting light are diminished and more light is absorbed with the addition of more PANI and $\mathrm{Fe}_{3} \mathrm{O}_{4}$ NPs into the coaxial nanoribbon array membrane. On the other hand, because PANI has different absorbances at different wavelengths of light, as well as $\mathrm{Fe}_{3} \mathrm{O}_{4}$ NPs, as seen in Fig. 11, the different wavelengths of light emitted from the coaxial nanoribbon array membrane are unequally absorbed by PANI and $\mathrm{Fe}_{3} \mathrm{O}_{4}$, thus the emitted colors are shifted.

From the contrast between the coaxial nanoribbon array membrane $\left(\mathrm{S}_{\mathrm{b} 1} @ \mathrm{~S}_{\mathrm{a} 4}\right)$ and $\mathrm{Fe}_{3} \mathrm{O}_{4} /\left[\mathrm{Eu}(\mathrm{TTA})_{3}(\mathrm{TPPO})_{2}+\right.$ $\left.\mathrm{Tb}(\mathrm{TTA})_{3}(\mathrm{TPPO})_{2}\right] /$ PANI/PMMA composite nanoribbon array membrane, as shown in Fig. 12, both the excitation and emission intensities of the coaxial nanoribbon array membrane are much stronger than those of the $\mathrm{Fe}_{3} \mathrm{O}_{4} /\left[\mathrm{Eu}(\mathrm{TTA})_{3}(\mathrm{TPPO})_{2}+\right.$ $\left.\mathrm{Tb}(\mathrm{TTA})_{3}(\mathrm{TPPO})_{2}\right] /$ PANI/PMMA composite nanoribbon array membrane. The emission intensity of the coaxial nanoribbon array membrane is about 100 times higher than that of the composite nanoribbon array membrane, which is due to the isolation of $\left[\mathrm{Eu}(\mathrm{TTA})_{3}(\mathrm{TPPO})_{2}+\mathrm{Tb}(\mathrm{TTA})_{3}(\mathrm{TPPO})_{2}\right]$ from the $\mathrm{Fe}_{3} \mathrm{O}_{4}$ NPs. $\left[\mathrm{Eu}(\mathrm{TTA})_{3}(\mathrm{TPPO})_{2}+\mathrm{Tb}(\mathrm{TTA})_{3}(\mathrm{TPPO})_{2}\right]$, PANI and $\mathrm{Fe}_{3} \mathrm{O}_{4}$ NPs are loosely mixed in the composite nanoribbon array membrane, as shown in Fig. 13, where RE(TTA $)_{3}(\mathrm{TPPO})_{2}(\mathrm{RE}=$ $\mathrm{Eu}$ and $\mathrm{Tb}$ ) directly contacts the $\mathrm{Fe}_{3} \mathrm{O}_{4}$ NPs which strongly absorb and weaken the excitation and emission light, leading to a severe decrease in luminescent intensity. On the contrary, in the coaxial nanoribbon array membrane, the $\mathrm{Fe}_{3} \mathrm{O}_{4}$ NPs are isolated from the $\operatorname{Eu}(\mathrm{TTA})_{3}(\mathrm{TPPO})_{2}$ and $\mathrm{Tb}(\mathrm{TTA})_{3}(\mathrm{TPPO})_{2}$ complexes in their own domains of the coaxial nanoribbon array membrane, therefore the excitation and emission light in the $\left\{\left[\mathrm{Eu}(\mathrm{TTA})_{3}(\mathrm{TPPO})_{2}+\mathrm{Tb}(\mathrm{TTA})_{3}(\mathrm{TPPO})_{2}\right] / \mathrm{PANI} / \mathrm{PMMA}\right\}$ domain are almost unaffected by the $\mathrm{Fe}_{3} \mathrm{O}_{4}$ NPs. This result fully shows that the coaxial nanoribbon array membrane exhibits a better fluorescent performance than the $\mathrm{Fe}_{3} \mathrm{O}_{4}$ / $\left[\mathrm{Eu}(\mathrm{TTA})_{3}(\mathrm{TPPO})_{2}+\mathrm{Tb}(\mathrm{TTA})_{3}(\mathrm{TPPO})_{2}\right] / \mathrm{PANI} / \mathrm{PMMA}$ composite

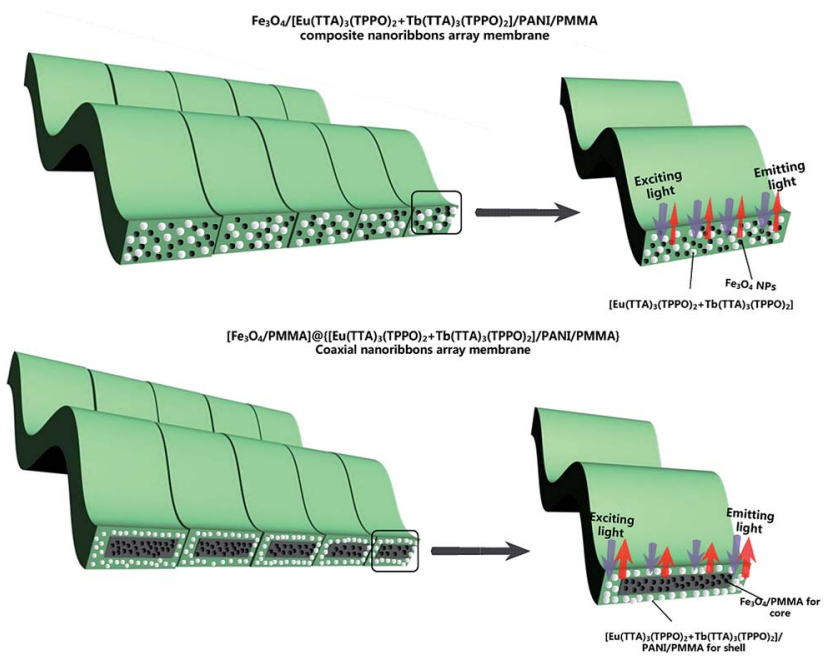

Fig. 13 Schematic diagram showing the excitation and emission light in the composite nanoribbon array membrane and $\left[\mathrm{Fe}_{3} \mathrm{O}_{4} / \mathrm{PMMA}\right] \mathrm{a}$ $\left\{\left[\mathrm{Eu}(\mathrm{TTA})_{3}(\mathrm{TPPO})_{2}+\mathrm{Tb}(\mathrm{TTA})_{3}(\mathrm{TPPO})_{2}\right] / P A N I / P M M A\right\}$ coaxial nanoribbon array membrane.

nanoribbon array membrane. Therefore, the higher luminescent intensity of the coaxial nanoribbon array membrane was obtained by separating $\mathrm{Eu}(\mathrm{TTA})_{3}(\mathrm{TPPO})_{2}$ and $\mathrm{Tb}(\mathrm{TTA})_{3}(\mathrm{TPPO})_{2}$ from the $\mathrm{Fe}_{3} \mathrm{O}_{4}$ NPs.

\subsection{Electrical conductivity analysis}

In order to study the anisotropic conductivity of the $\left[\mathrm{Fe}_{3} \mathrm{O}_{4} /\right.$ PMMA $] @\left\{\left[\mathrm{Eu}(\mathrm{TTA})_{3}(\mathrm{TPPO})_{2}+\mathrm{Tb}(\mathrm{TTA})_{3}(\mathrm{TPPO})_{2}\right] / \mathrm{PANI} / \mathrm{PMMA}\right\}$ coaxial nanoribbon array membrane and composite nanoribbon array membrane, a piece of soldering tin was cut into two pieces with length and width of $c a .1 \mathrm{~cm}$ and $c a .0 .5 \mathrm{~cm}$, respectively, and then the two pieces of soldering were pressed onto the nanoribbon array membrane, as indicated in Fig. 14. Subsequently, the four pins of a Hall Effect Measurement System were pressed on the two pieces of soldering tin. The relationships of voltage and current between P1 and P3 and P2 and $\mathrm{P} 4$ were recorded by the Hall Effect Measurement System, and the results are presented in Fig. 15. It can be seen that the
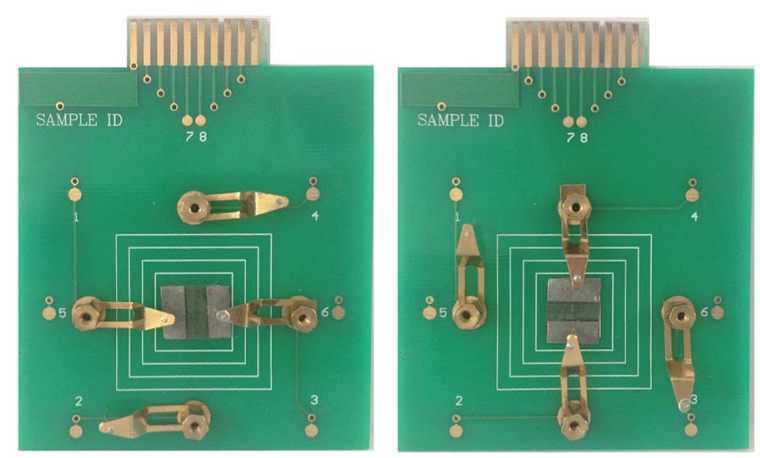

Fig. 14 Arrangement of the four contact points on the $\left[\mathrm{Fe}_{3} \mathrm{O}_{4} / \mathrm{PMMA}\right]$ ( $\left\{\left[\mathrm{Eu}(T T A)_{3}(\mathrm{TPPO})_{2}+\mathrm{Tb}(\mathrm{TTA})_{3}(\mathrm{TPPO})_{2}\right] / P A N I / P M M A\right\}$ coaxial nanoribbon array membrane. 

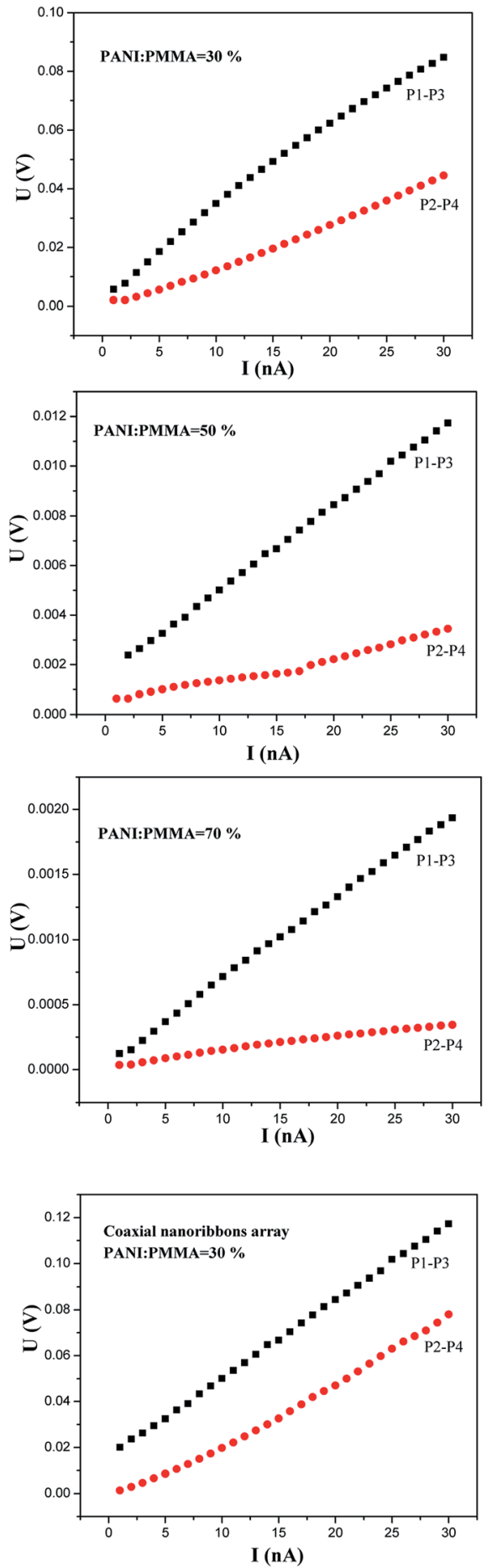

Fig. 15 Relationships between the voltage and current of the samples doped with various amounts of PANI between P1 and P3 and P2 and P4.

conductance parallel to the length direction of the nanoribbons (P1-P3) is higher than that perpendicular to the length direction of the nanoribbons (P2-P4), which demonstrates that the coaxial nanoribbon array membrane possesses anisotropic conductivity. Since each coaxial nanoribbon has a conductivephotoluminescent shell and nearly all the broadsides of the
Table 4 Conductivity of the samples containing different amounts of PANI between P1 and P3 and P2 and P4

\begin{tabular}{|c|c|c|c|}
\hline \multirow[b]{2}{*}{ Samples } & \multicolumn{3}{|c|}{ Conductivity $\left(\mathrm{S} \mathrm{cm}^{-1}\right)$} \\
\hline & Parallel $(X)(\mathrm{P} 1-\mathrm{P} 3)$ & $\begin{array}{l}\text { Perpendicular } \\
(Y)(\mathrm{P} 2-\mathrm{P} 4)\end{array}$ & $X / Y$ \\
\hline $\begin{array}{l}\text { Composite } \\
\text { nanoribbon array } \\
\text { membrane }\end{array}$ & $4.795 \times 10^{-7}$ & $2.054 \times 10^{-7}$ & 2.33 \\
\hline $\mathrm{S}_{\mathrm{b} 1} @ \mathrm{~S}_{\mathrm{a} 4}(30 \%)$ & $7.819 \times 10^{-7}$ & $3.048 \times 10^{-7}$ & 2.57 \\
\hline $\mathrm{S}_{\mathrm{b} 1} @ \mathrm{~S}_{\mathrm{a} 8}(50 \%)$ & $7.588 \times 10^{-6}$ & $2.238 \times 10^{-6}$ & 3.39 \\
\hline $\mathrm{S}_{\mathrm{b} 1} @ \mathrm{~S}_{\mathrm{a} 9}(70 \%)$ & $7.143 \times 10^{-5}$ & $1.452 \times 10^{-5}$ & 4.92 \\
\hline
\end{tabular}

Table 5 Saturation magnetization of the composite nanoribbon array membrane and $\left[\mathrm{Fe}_{3} \mathrm{O}_{4} / \mathrm{PMMA}\right] @\left\{\left[\mathrm{Eu}(\mathrm{TTA})_{3}(\mathrm{TPPO})_{2}+\mathrm{Tb}(\mathrm{TTA})_{3}(-\right.\right.$ TPPO $)_{2}$ ]/PANI/PMMA\} coaxial nanoribbon array membrane

\begin{tabular}{ll}
\hline Sample & $\begin{array}{l}\text { Saturation magnetization } \\
\left(M_{\mathrm{s}}\right) / \mathrm{emu} \mathrm{g}^{-1}\end{array}$ \\
\hline $\begin{array}{l}\text { Composite nanoribbons array } \\
\text { membrane }\end{array}$ & 3.74 \\
$\mathrm{~S}_{\mathrm{b} 1} @ \mathrm{~S}_{\mathrm{a}_{4}}\left(\mathrm{Fe}_{3} \mathrm{O}_{4}:\right.$ PMMA $\left.=1: 1\right)$ & 4.23 \\
$\mathrm{~S}_{\mathrm{b} 2} @ \mathrm{~S}_{\mathrm{a} 4}\left(\mathrm{Fe}_{3} \mathrm{O}_{4}:\right.$ PMMA $\left.=2: 1\right)$ & 5.82 \\
$\mathrm{~S}_{\mathrm{b} 3} @ \mathrm{~S}_{\mathrm{a} 4}\left(\mathrm{Fe}_{3} \mathrm{O}_{4}: \mathrm{PMMA}=3: 1\right)$ & 8.23
\end{tabular}

coaxial nanoribbons face upwards, electrons can move along the length direction of the nanoribbons, whereas some interfaces among the coaxial nanoribbons hinder the movement of electrons to some extent along with perpendicular direction. The conductivities of coaxial nanoribbon array membranes containing different amounts of PANI between P1 and P3 and P2 and P4 are tabulated in Table 4. Evidently, with an increase in the dosage of PANI introduced into the coaxial nanoribbons array membrane, higher conductivity can be achieved in the coaxial nanoribbon array membrane. Its conductivity parallel to the length direction of the nanoribbons is $c a$. two to five times higher than that perpendicular to the length direction of the nanoribbons. Thus, the anisotropic electrical conductivity of the coaxial nanoribbon array membrane can be tuned because PANI is consecutive in the shell of coaxial nanoribbon array membrane and may form a conducting network more easily, which renders more efficient charge transport.

The $\mathrm{Fe}_{3} \mathrm{O}_{4} /\left[\mathrm{Eu}(\mathrm{TTA})_{3}(\mathrm{TPPO})_{2}+\mathrm{Tb}(\mathrm{TTA})_{3}(\mathrm{TPPO})_{2}\right] / \mathrm{PANI} /$ PMMA composite nanoribbon array membrane has weak anisotropic conductivity. Its conductivity parallel to the length direction of the nanoribbons is about two times higher than that perpendicular to the length direction of the nanoribbons. Additionally, the conductivity of the $\mathrm{Fe}_{3} \mathrm{O}_{4} /\left[\mathrm{Eu}(\mathrm{TTA})_{3}(\mathrm{TPPO})_{2}+\right.$ $\left.\mathrm{Tb}(\mathrm{TTA})_{3}(\mathrm{TPPO})_{2}\right] / \mathrm{PANI} / \mathrm{PMMA}$ composite nanoribbon array membrane is lower than that of coaxial nanoribbon array membrane (sample $\mathrm{S}_{\mathrm{b} 1} @ \mathrm{~S}_{\mathrm{a} 4}$ ) under the same components and contents of the two types of nanostructures. The reason for this is probably that insulative materials such as $\mathrm{Fe}_{3} \mathrm{O}_{4}$ NPs and $\mathrm{RE}(\mathrm{TTA})_{3}(\mathrm{TPPO})_{2}(\mathrm{RE}=\mathrm{Eu}$ and $\mathrm{Tb})$ are dispersed in the $\mathrm{Fe}_{3} \mathrm{O}_{4} /$ 


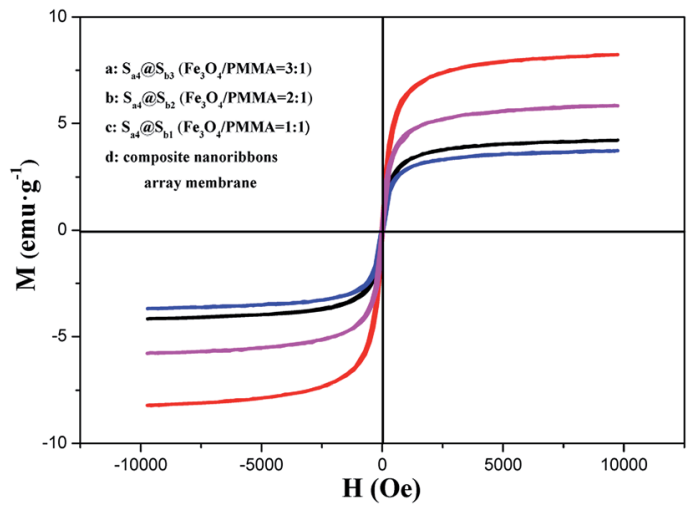

Fig. 16 Hysteresis loops of the composite nanoribbon array membranes and $\left[\mathrm{Fe}_{3} \mathrm{O}_{4} / \mathrm{PMMA}\right] @\left\{\left[\mathrm{Eu}(\mathrm{TTA})_{3}(\mathrm{TPPO})_{2}+\mathrm{Tb}(T T A)_{3}(-\right.\right.$ TPPO) ${ }_{2}$ ]/PANI/PMMA\} coaxial nanoribbon array membrane.

$\left[\mathrm{Eu}(\mathrm{TTA})_{3}(\mathrm{TPPO})_{2}+\mathrm{Tb}(\mathrm{TTA})_{3}(\mathrm{TPPO})_{2}\right] /$ PANI/PMMA composite nanoribbon array membrane, which hinders the formation of a continuous conductive network.

\subsection{Magnetic property}

Fig. 16 reveals the hysteresis loops for the $\mathrm{Fe}_{3} \mathrm{O}_{4} /\left[\mathrm{Eu}(\mathrm{TTA})_{3}(-\right.$ TPPO $\left.)_{2}+\mathrm{Tb}(\mathrm{TTA})_{3}(\mathrm{TPPO})_{2}\right] / \mathrm{PANI} / \mathrm{PMMA}$ composite nanoribbon array membranes and the $\left[\mathrm{Fe}_{3} \mathrm{O}_{4} / \mathrm{PMMA}\right] @\left\{\left[\mathrm{Eu}(\mathrm{TTA})_{3}(\mathrm{TPPO})_{2}+\right.\right.$ $\left.\left.\mathrm{Tb}(\mathrm{TTA})_{3}(\mathrm{TPPO})_{2}\right] / \mathrm{PANI} / \mathrm{PMMA}\right\}$ coaxial nanoribbon array membrane containing various mass ratios of $\mathrm{Fe}_{3} \mathrm{O}_{4} \mathrm{NPs}$, and the data are given in Table 5 . It is found that the saturation magnetization of the $\left[\mathrm{Fe}_{3} \mathrm{O}_{4} / \mathrm{PMMA}\right] @\left\{\left[\mathrm{Eu}(\mathrm{TTA})_{3}(\mathrm{TPPO})_{2}+\right.\right.$ $\left.\left.\mathrm{Tb}(\mathrm{TTA})_{3}(\mathrm{TPPO})_{2}\right] / \mathrm{PANI} / \mathrm{PMMA}\right\}$ coaxial nanoribbon array membrane increases with the incorporating of more $\mathrm{Fe}_{3} \mathrm{O}_{4} \mathrm{NPs}$ in the core, which indicates that the magnetism of the coaxial nanoribbon array membrane can be modulated. Besides, the saturation magnetization of the coaxial nanoribbon array membrane $\left(\mathrm{S}_{\mathrm{b} 1} @ \mathrm{~S}_{\mathrm{a} 4}\right)$ is $4.23 \mathrm{emu} \mathrm{g}^{-1}$ which is close to that of its counterpart $\mathrm{Fe}_{3} \mathrm{O}_{4} /\left[\mathrm{Eu}(\mathrm{TTA})_{3}(\mathrm{TPPO})_{2}+\mathrm{Tb}(\mathrm{TTA})_{3}(\mathrm{TPPO})_{2}\right] / \mathrm{PANI} /$ PMMA composite nanoribbon array membrane $(3.74$ emu $\left.\mathrm{g}^{-1}\right)$. By combining the analyses of magnetism, electrical conductivity and fluorescence, it is found that the coaxial nanoribbon array membrane has similar magnetic properties to the composite nanoribbon array membrane, whereas the fluorescent intensity and anisotropic electrical conductivity of the coaxial nanoribbon array membrane is much higher than that of the composite nanoribbon array membrane, which further indicates that the coaxial nanoribbon array membrane possess better luminescent-electrical-magnetic performance than its counterpart composite nanoribbon array membrane.

\section{Conclusions}

A novel 2D multicolor luminescent array membrane $\left[\mathrm{Fe}_{3} \mathrm{O}_{4} /\right.$ PMMA $] @\left\{\left[\mathrm{Eu}(\mathrm{TTA})_{3}(\mathrm{TPPO})_{2}+\mathrm{Tb}(\mathrm{TTA})_{3}(\mathrm{TPPO})_{2}\right] / \mathrm{PANI} / \mathrm{PMMA}\right\}$ endowed with tunable anisotropic electrical conductivity and magnetism was successfully fabricated via electrospinning using a specially designed and assembled coaxial spinneret. The 2D multicolor luminescent array membrane is assembled by $1 \mathrm{D}$ coaxial nanoribbons, in which the coaxial nanoribbons are arranged in the same direction and all their broadsides nanoribbons face upwards. Each coaxial nanoribbon in the array is composed of an $\mathrm{Fe}_{3} \mathrm{O}_{4} / \mathrm{PMMA}$ magnetic core and $\left[\mathrm{Eu}(\mathrm{TTA})_{3}(\mathrm{TPPO})_{2}+\mathrm{Tb}(\mathrm{TTA})_{3}(\mathrm{TPPO})_{2}\right] / \mathrm{PANI} / \mathrm{PMMA}$ conductivephotoluminescent shell. Delightfully, tunable colors from green to red emission colors can be obtained by modulating the molar ratio of $\mathrm{Eu}^{3+}$ and $\mathrm{Tb}^{3+}$ as well as the ratio of PANI and $\mathrm{Fe}_{3} \mathrm{O}_{4}$. This unique nanostructure greatly promotes conductive anisotropy, in which the ratio of conductivity parallel and perpendicular to the length direction of the nanoribbons is as high as five. The anisotropic electrical conductivity and magnetism of the coaxial nanoribbons array membrane can be adjusted by modulating the contents of PANI and $\mathrm{Fe}_{3} \mathrm{O}_{4}$ NPs. This work presents an excellent method for the fabrication of innovative 2D multifunctional nanocomposites possessing anisotropic electrical conductivity and magnetism, which have possible applications in many future fields, such as in mobile phones and subminiature integrated circuits.

\section{Acknowledgements}

This work was financially supported by National Natural Science Foundation of China (51573023, 50972020), Natural Science Foundation of Jilin Province (20170101101JC), the Open Project Program of Key Laboratory of Preparation and Application of Environmentally Friendly Materials (Jilin Normal University), Ministry of Education, China (No. 2017003), Youth Foundation of Changchun University of Science and Technology (No. XQNJJ-2016-01).

\section{Notes and references}

1 F. Wang, Y. Han, C. S. Lim, Y. Lu, J. Wang, J. Xu, H. Chen, C. Zhang, M. Hong and X. Liu, Nature, 2010, 463, 1061-1065.

2 K. S. Sohn, J. M. Lee and N. Shin, Adv. Mater., 2003, 15, 20812084.

3 P. Yang, S. Gai and J. Lin, Chem. Soc. Rev., 2012, 41, 36793698.

4 S. Gai, P. Yang, C. Li, W. Wang, Y. Dai, N. Niu and J. Lin, Adv. Funct. Mater., 2010, 20, 1166-1172.

5 S. Huang, J. Xu, Z. Zhang, X. Zhang, L. Wang, S. Gai, F. He, N. Niu, M. Zhang and P. Yang, J. Mater. Chem., 2012, 22, 16136-16144.

6 N. Niu, P. Yang, F. He, X. Zhang, S. Gai, C. Li and J. Lin, J. Mater. Chem., 2012, 22, 10889-10899.

7 S. Zhou, W. Zheng, Z. Chen, D. Tu, Y. Liu, E. Ma, R. Li, H. Zhu, M. Huang and X. Chen, Angew. Chem., Int. Ed., 2014, 53, 12498-12502.

8 D. Yin, X. Cao, L. Zhang, J. Tang, W. Huang, Y. Han and M. Wu, Dalton Trans., 2015, 44, 11147-11154.

9 Y. Liu, D. Tu, H. Zhu and X. Chen, Chem. Soc. Rev., 2013, 42, 6924-6958.

10 C. C. Lin and R.-S. Liu, J. Phys. Chem. Lett., 2011, 2, 12681277.

11 K. Li, Y. Zhang, X. Li, M. Shang, H. Lian and J. Lin, Phys. Chem. Chem. Phys., 2015, 17, 4283-4292. 
12 H. Liu, T. Chu, Z. Rao, S. Wang, Y. Yang and W.-T. Wong, Adv. Opt. Mater., 2015, 3, 1545-1550.

13 X. Zhang and M. Gong, Ind. Eng. Chem. Res., 2015, 54, 76327639.

14 M. Zhang, Y. Liang, R. Tang, D. Yu, M. Tong, Q. Wang, Y. Zhu, X. Wu and G. Li, RSC Adv., 2014, 4, 40626-40637.

15 P. Huang, W. Zheng, S. Zhou, D. Tu, Z. Chen, H. Zhu, R. Li, E. Ma, M. Huang and X. Chen, Angew. Chem., Int. Ed., 2014, 53, 1252-1257.

16 P. Chen, Q. Li, S. Grindy and N. Holten-Andersen, J. Am. Chem. Soc., 2015, 137, 11590-11593.

17 X. Liu, W. Hou, X. Yang and J. Liang, CrystEngComm, 2014, 16, 1268-1276.

18 S. Xu, P. Li, Z. Wang, T. Li, Q. Bai, J. Sun and Z. Yang, J. Mater. Chem. C, 2015, 3, 9112-9121.

19 C. Zeng, Y. Hu, Z. Xia and H. Huang, RSC Adv., 2015, 5, 68099-68108.

20 R. Li, G. Yu, Y. Liang, N. Zhang, Y. Liu and S. Gan, J. Colloid Interface Sci., 2015, 460, 273-280.

21 R. Li, L. Li, Y. Liang, N. Zhang, Y. Liu and S. Gan, Phys. Chem. Chem. Phys., 2015, 17, 21485-21491.

22 Z. Leng, H. Xiong, L. Li, N. Zhang, Y. Liu and S. Gan, J. Alloys Compd., 2015, 646, 632-638.

23 L. Liu, Y. Liang, L. Li, L. Zou and S. Gan, CrystEngComm, 2015, 17, 7754-7761.

24 Y. R. Weng, J. Zhao, S. Y. Yu and S. Y. Song, CrystEngComm, 2014, 16, 6257-6262.

25 Y. Gong, J. Dai, H. Li, X. Wang, H. Xiong, Q. Zhang, P. Li, C. Yi, Z. Xu, H. Xu and P. K. Chu, J. Biomater. Appl., 2015, 30, 201-211.

26 D. Li, Q. Ma, X. Xi, X. Dong, W. Yu, J. Wang and G. Liu, Chem. Eng. J., 2017, 309, 230-239.

27 B. Li, Y.-C. Zhang, Z.-M. Li, S.-N. Li and X.-N. Zhang, J. Phys. Chem. B, 2010, 114, 689-696.

28 Y. J. Jung, S. Kar, S. Talapatra, C. Soldano, G. Viswanathan, X. Li, Z. Yao, F. S. Ou, A. Avadhanula, R. Vajtai, S. Curran, O. Nalamasu and P. M. Ajayan, Nano Lett., 2006, 6, 413-418.

29 E. J. Ra, K. H. An, K. K. Kim, S. Y. Jeong and Y. H. Lee, Chem. Phys. Lett., 2005, 413, 188-193.

30 S. Gong, Z. H. Zhu and S. A. Meguid, Polymer, 2015, 56, 498506.

31 S. Sheng, Q. Ma, X. Dong, N. Lv, J. Wang, W. Yu and G. Liu, J. Mater. Sci.: Mater. Electron., 2014, 25, 1309-1316.

32 S. Sheng, Q. Ma, X. Dong, N. Lv, J. Wang, W. Yu and G. Liu, J. Mater. Sci.: Mater. Electron., 2014, 25, 2279-2286.

33 Y. Liu, Q. Ma, M. Yang, X. Dong, Y. Yang, J. Wang, W. Yu and G. Liu, Chem. Eng. J., 2016, 284, 831-840.
34 Y. Liu, Q. Ma, X. Dong, W. Yu, J. Wang and G. Liu, Phys. Chem. Chem. Phys., 2015, 17, 22977-22984.

35 K. Lun, Q. Ma, M. Yang, X. Dong, Y. Yang, J. Wang, W. Yu and G. Liu, Chem. Eng. J., 2015, 279, 231-240.

36 L. Jiang, S. Yinghui, H. Peng, L.-J. Li, T. Wu, J. Ma, F. Y. Chiang Boey, X. Chen and L. Chi, Small, 2011, 7, 1949-1953.

37 J. Zhou, J. Zeng, J. Grant, H. Wu and Y. Xia, Small, 2011, 7, 3308-3316.

38 L. Han, Q. Ma and X. Dong, RSC Adv., 2015, 5, 95674-95681.

39 F. Bi, X. Dong, J. Wang and G. Liu, New J. Chem., 2015, 39, 3444-3451.

40 D. Yin, Q. Ma, X. Dong, N. Lv, J. Wang, W. Yu and G. Liu, ChemPlusChem, 2015, 80, 568-575.

41 F. Bi, X. Dong, J. Wang and G. Liu, ChemPlusChem, 2014, 79, 1713-1719.

42 X. Xi, Q. Ma, X. Dong, J. Wang, W. Yu and G. Liu, IEEE Trans. Nanotechnol., 2015, 14, 243-249.

43 W. Sambaer, M. Zatloukal and D. Kimmer, Chem. Eng. Sci., 2011, 66, 613-623.

44 J. M. Corres, Y. R. Garcia, F. J. Arregui and I. R. Matias, IEEE Sens. J., 2011, 11, 2383-2387.

45 A. Townsend-Nicholson and S. N. Jayasinghe, Biomacromolecules, 2006, 7, 3364-3369.

46 K. Xu, S. Li, J. Yang, H. Xu and J. Hu, J. Alloys Compd., 2016, 678, 120-125.

47 Z. Wang, Q. Ma, X. Dong, D. Li, X. Xi, W. Yu, J. Wang and G. Liu, ACS Appl. Mater. Interfaces, 2016, 8, 26226-26234.

48 Z. Wang, Q. Ma, X. Dong, D. Li, X. Xi, W. Yu, J. Wang and G. Liu, Phys. Chem. Chem. Phys., 2017, 19, 118-126.

49 D. Zhang, J. Cheng, X. Yang, B. Zhao and M. Cao, J. Mater. Sci., 2014, 49, 7221-7230.

50 Q. Ma, J. Wang, X. Dong, W. Yu and G. Liu, RSC Adv., 2015, 5, 2523-2530.

51 J. Song, M. Chen, M. B. Olesen, C. Wang, R. Havelund, Q. Li, E. Xie, R. Yang, P. Boggild, C. Wang, F. Besenbacher and M. Dong, Nanoscale, 2011, 3, 4966-4971.

52 S. Palaniappan and M. Sairam, J. Appl. Polym. Sci., 2008, 108, 825-832.

53 Y. Xia, J. M. Wiesinger, A. G. MacDiarmid and A. J. Epstein, Chem. Mater., 1995, 7, 443-445.

54 S. Sheng, Q. Ma, X. Dong, N. Lv, J. Wang, W. Yu and G. Liu, J. Mater. Sci.: Mater. Electron., 2014, 25, 2279-2286.

55 L. Chittka, J. Comp. Physiol., A, 1992, 170, 533-543.

56 A. R. Robertson, Color Res. Appl., 1977, 2, 7-11.

57 Q. Ma, W. Yu, X. Dong, J. Wang and G. Liu, Nanoscale, 2014, 6, 2945-2952. 